\title{
Brain Region Specific Monoamine and Oxidative Changes During Restraint Stress
}

\author{
Ausaf Ahmad, Naila Rasheed, Ghulam Md Ashraf, Rajnish Kumar, Naheed Banu, \\ Farah Khan, Muneera Al-Sheeha, Gautam Palit
}

\begin{abstract}
Background and Purpose: Stress-induced central effects are regulated by brain neurotransmitters, glucocorticoids and oxidative processes. Therefore, we aimed to evaluate the simultaneous alterations in the monoamine and antioxidant systems in selected brain regions (frontal cortex, striatum and hippocampus) at 1 hour (h) and $24 \mathrm{~h}$ following the exposure of restraint stress (RS), to understand their initial response and possible crosstalk. Methods and Results: RS (150 min immobilization) significantly increased the dopamine levels in the frontal cortex and decreased them in the striatum and hippocampus, with selective increase of dopamine metabolites both in the $1 \mathrm{~h}$ and $24 \mathrm{~h}$ RS groups compared to control values. The serotonin and its metabolite levels were significantly increased in both time intervals, while noradrenaline levels were decreased in the frontal cortex and striatum only. The activities of superoxide dismutase, glutathione peroxidase and the levels of lipid peroxidation were significantly increased with significant decrease of glutathione levels in the frontal cortex and striatum both in the $1 \mathrm{~h}$ and $24 \mathrm{~h}$ RS groups. There was no significant change in the catalase activity in any group. In the hippocampus, the glutathione levels were significantly decreased only in the $1 \mathrm{~h}$ RS group. Conclusions: Our study implies that the frontal cortex and striatum are more sensitive to oxidative burden which could be related to the parallel monoamine perturbations. This provides a rational look into the simultaneous compensatory central mechanisms operating during acute stress responses which are particular to precise brain regions and may have long lasting effects on various neuropathological alterations.
\end{abstract}

RÉSUMÉ: Changements au niveau des monoamines et changements oxydatifs spécifiques à certaines régions du cerveau pendant le stress de contention. Contexte et objectif : Les effets centraux induits par le stress sont régulés par les neurotransmetteurs cérébraux, les glucocorticoïdes et les processus oxydatifs. Notre but était d'évaluer les changements simultanés dans les systèmes des monoamines et des antioxydants dans des régions particulières du cerveau (cortex frontal, striatum et hippocampe) 1 heure (h) et $24 \mathrm{~h}$ après une exposition à un stress de contention (SC) afin de comprendre la réponse initiale et l'intermodulation s'il y a lieu. Méthode et résultats : Le SC (immobilisation de 150 minutes) augmentait les niveaux de dopamine de façon significative dans le cortex frontal et les diminuait dans le striatum et l'hippocampe, et il augmentait de façon sélective certains métabolites de la dopamine tant après $1 \mathrm{~h}$ qu'après $24 \mathrm{~h}$ par rapport aux valeurs témoins. Les niveaux de sérotonine et de ses métabolites étaient augmentés de façon importante après $1 \mathrm{~h}$ et $24 \mathrm{~h}$ et les niveaux de noradrénaline étaient diminués dans le cortex frontal et le striatum seulement. L'activité de la superoxyde dismutase, de la glutathion peroxydase et les niveaux de peroxydation lipidique étaient augmentés de façon importante, tandis que les niveaux de glutathion étaient diminués de façon importante dans le cortex frontal et le striatum après $1 \mathrm{~h}$ et après $24 \mathrm{~h}$. Aucun changement significatif de l'activité de la catalase n'a été observé. Dans l'hippocampe, les niveaux de glutathion étaient diminués de façon significative seulement après 1 h. Conclusions : Selon ces observations, le cortex frontal et le striatum seraient plus sensibles au fardeau oxydatif ce qui pourrait être relié aux perturbations parallèles des monoamines. Notre étude donne un aperçu rationnel des mécanismes compensatoires centraux simultanés, qui existent pendant les réponses au stress aigu, et qui sont particuliers à des régions précises du cerveau. Ils pourraient avoir des effets à long terme sur différents changements neuropathologiques.

Can J Neurol Sci. 2012; 39: 311-318

Stress-induced changes in the monoaminergic system and subsequent enhancement of oxidative load are associated with a wide range of central and peripheral disorders ${ }^{1-3}$. Exposure to a single session of severe uncontrollable foot shock was reported to cause protracted changes in dogs and rats, which are now characterized as anxiety and depression-like changes ${ }^{4}$. Reports also suggested alterations in the physiological parameters like body temperature, locomotion and exploratory behaviour ${ }^{5}$, hypothalamus-pituitary-adrenal (HPA)-axis ${ }^{2}$ and brain neurotransmitters ${ }^{5,6}$ in animals acutely exposed to unfamiliar stress. However, there is little information regarding the acute stressinduced central oxidative changes in terms of their initial response and vulnerability in different brain regions and the findings are conflicting ${ }^{7-9}$. Most of the studies have used chronic stress models to examine the stress-induced pathologies, as they

\footnotetext{
From the Amity Institute of Biotechnology (AA, RK), Amity University Uttar Pradesh, Lucknow, Uttar Pradesh; College of Medicine (NR, MAS), Qassim University, Buraidah, KSA; Department of Biochemistry (NB), Faculty of Life Sciences, A.M. University, Aligarh; Department of Biochemistry (FK), Faculty of Science, Jamia Hamdard University, New Delhi; Division of Pharmacology (AA, NR, GP), Central Drug Research Institute, Lucknow, India; King Fahd Medical Research Center (GMA), King Abdulaziz University, Jeddah, Kingdom of Saudi Arabia.

Received April 29, 2011. Final Revisions Submitted December 22, 2011 Correspondence to: Ausaf Ahmad, Amity Institute of Biotechnology, Amity University Uttar Pradesh, Lucknow-226010, Uttar Pradesh, India.
}

Email: ausafahmad@rediffmail.com 
simulate human-related clinical conditions. However, examining the effect of single stress exposure on the central nervous system at different time intervals is also crucial. This may help in determining which of the central systems (monoamines or oxidative processes) is more sensitive to stress; which brain regions show pronounced changes; and how long these changes exist.

The brain is more vulnerable to oxidative damage compared to other organs as it has a higher rate of oxygen consumption per unit mass of tissue, contains high levels of peroxidizable lipids, excitotoxic amino acids and low levels of antioxidants ${ }^{1,3}$. Some studies indicate a link between the alterations in the central monoaminergic systems and increased oxidative load during physiologically adverse conditions ${ }^{10,11}$. However, the extent to which oxidation products contribute to the perturbed redox state during acute stressful condition in the brain regions with monoaminergic innervation is still unclear. Furthermore, except for a few in vitro studies indicating the pro-oxidant effect of phenol-containing neurotransmitters, animal studies that address the simultaneous changes in the brain monoamine levels and antioxidant defense system are lacking ${ }^{11}$.

The frontal cortex and striatum have a high dopamine (DA) content ${ }^{12}$, while the hippocampus has a high concentration of glucocorticoids (GC) receptors ${ }^{2}$. These brain regions are connected with each other through different neurotransmitter systems and have been proposed to play an important modulatory role in stress responses ${ }^{2}$. In the present study, we hypothesized that these brain regions could be particularly vulnerable to stress exposure, and that changes in central monoamine and antioxidant systems could be interrelated. It was also hypothesized that the source of oxidative damage during stress may vary in a region and time specific manner depending on the microenvironment of the brain region.

Therefore, the aim of the present investigation was to evaluate the response of monoamines and their metabolite concentrations with simultaneous changes in the enzymatic and non-enzymatic antioxidant defense systems and lipid peroxidation in the selected brain regions at 1 hour (h) and $24 \mathrm{~h}$ following the exposure of restraint stress $(\mathrm{RS})$ in rats. In order to evaluate oxidative alterations during RS, we measured the activities of $\mathrm{Cu}-\mathrm{Zn}$ superoxide dismutase (SOD), catalase (CAT), selenium dependent glutathione peroxidase (GSH-Px), extent of lipid peroxidation (Malondialdehyde concentrations) and reduced glutathione (GSH) concentrations in the selected brain regions.

\section{Methods}

\section{Animals}

Experimental protocols were approved by the Institutional Ethical and Usage Committee of Central Drug Research Institute (CDRI), Lucknow, following the guidelines of the Committee for the Purpose of Control and Supervision of Experiments on Animals (CPCSEA). Adult male Sprague Dawley rats, weighing $180-220 \mathrm{~g}$ procured from National Laboratory Animal Centre, CDRI, were used in the study. For both control and stressed groups three rats were housed per cage, in a room with temperature regulated at $22 \pm 2^{\circ} \mathrm{C}$, with a $12 \mathrm{~h} / 12 \mathrm{~h}$ light/dark cycle (lights on 07:00 h, lights off 19:00 h). Standard chow pellets and water were given ad libitum, except during the period when food or water deprivation was applied.

\section{Chemicals}

Dopamine (DA), dihydroxyphenylacetic acid (DOPAC), homovanillic acid (HVA), serotonin (5-HT), 5-hydroxyindole acetic acid (5-HIAA), dihydroxybenzylamine (DHBA), norepinephrine (NE), epinephrine, t-butyl hydroperoxide, reduced glutathione (GSH), glutathione reductase, thiobarbituric acid, 1,3,3 -tetraethoxypropane and 5, 5'-dithiobis (2nitrobenzoic acid) (DTNB) were purchased from Sigma Aldrich (St. Louis, MO, USA). All other chemicals used in the study were of analytical or high performance liquid chromatography (HPLC) grade and were purchased locally.

\section{Experimental protocol}

All the rats were acclimatized to laboratory conditions prior to the experiment. The rats were randomly divided into two groups i.e. a control non-stress (NS) and restraint stress (RS) group.

NS group: Rats were kept undisturbed in their home cages. Standard chow pellets and water were given ad libitum.

$\boldsymbol{R S}$ groups: In RS model, after $12 \mathrm{hr}$ fasting (food deprivation) of rats, one stress session consisting of a $2.5 \mathrm{hr}$ immobilization period inside the cylindrical steel tube $(7 \mathrm{~cm}$ diameter, $17.5 \mathrm{~cm}$ long, with holes for ventilation) at room temperature was performed during the early phase (7:00 a.m. to 9:30 a.m.) of the light cycle ${ }^{13}$. The RS group was further divided into two groups, based upon the time of killing the rats after the stress regimen. In one group rats were killed $1 \mathrm{~h}$ after the stressor (1h RS group), the other group was killed $24 \mathrm{~h}$ after the stressor (24h RS group).

\section{Sample preparation}

The rats were killed by conscious cervical dislocation followed by decapitation, and the brains were immediately removed. The discrete brain regions (frontal cortex, striatum and hippocampus) were dissected on an ice-cold glass plate ${ }^{14}$. For the estimation of neurotransmitter levels the dissected brain regions were weighed and an internal standard DHBA (25 $\mathrm{ng} / \mathrm{ml}$ ) was added to each sample. Homogenization was performed in $0.17 \mathrm{M}$ perchloric acid with an Ultra-Turrax homogenizer (Model T25, IKA-Laborthechnik, Staufen, Germany). The homogenates were then centrifuged at $35000 \mathrm{~g}$ (Model 3K30, Sigma Centrifuge, Osterode, Germany) at $4^{\circ} \mathrm{C}$, supernatants were passed through a $0.22 \mu \mathrm{m}$ membrane filter and were used for analysis. For the estimations of antioxidant parameters and lipid peroxidation, the dissected brain regions were homogenized in ice cold $50 \mathrm{mM}$ phosphate buffer ( $\mathrm{pH} 7.0$ ) containing $0.1 \mathrm{mM}$ ethylenediaminetetraacetic acid (EDTA) and centrifuged at $1000 \mathrm{~g}$ for $15 \mathrm{~min}$ at $4^{\circ} \mathrm{C}$, the supernatants thus obtained were used for the analysis.

\section{Estimation of monoamines and their metabolites}

The endogenous levels of NE, DA, 5-HT and their nonconjugated metabolites DOPAC, HVA, and 5-HIAA were determined by reverse phase HPLC with electrochemical detection ${ }^{15}$. The sample $(20 \mu \mathrm{L})$ was injected via an HPLC pump 
(Model 1525, Binary Gradient Pump, Waters, Milford, MA, U.S.A.) into a column (Spherisorb, RP C18, $5 \mu \mathrm{m}$ particle size, $4.6 \mathrm{~mm}$ i.d $\times 250 \mathrm{~mm}$ at $30^{\circ} \mathrm{C}$ ) connected to an electrochemical detector (Model 2465, Waters, Milford, MA, U.S.A.). Oxidation potential was fixed at $0.80 \mathrm{~V}$ using a glass carbon working electrode versus an $\mathrm{Ag} / \mathrm{AgCl}$ reference electrode. The mobile phase consisted of $32 \mathrm{mM}$ citric acid, $12.5 \mathrm{mM}$ disodium hydrogen orthophosphate, $1.4 \mathrm{mM}$ sodium octanyl sulfonate, $0.05 \mathrm{mM}$ EDTA and $16 \%(\mathrm{v} / \mathrm{v})$ methanol. The $\mathrm{pH}$ of the mobile phase was adjusted to 4.05 . Separation was carried out at a flow rate of $1.2 \mathrm{ml} / \mathrm{min}$. The neurotransmitters were quantified using Breeze version 3.2. The levels were expressed in nanograms of neurotransmitter per gram of wet weight of the brain tissue. Quantification was made by comparing peak heights of the samples to the corresponding standard curve.

\section{$\mathrm{Cu}-\mathrm{Zn}$, superoxide dismutase (SOD, EC 1.15.1.1) activity}

SOD activity was measured based on its ability to inhibit the autoxidation of epinephrine to adrenochrome at alkaline $\mathrm{pH}^{16}$. The absorbance of reaction mixture was followed for $4 \mathrm{~min}$ at $480 \mathrm{~nm}$ in a spectrophotometer (Model 1201, Shimadzu). Enzymatic activity was expressed as $\mathrm{U} / \mathrm{mg}$ protein at $30^{\circ} \mathrm{C}$. The amount of enzyme that caused $50 \%$ inhibition of epinephrine autoxidation was defined as one unit (U).

\section{Catalase (CAT, EC 1.11.1.6) activity}

CAT activity was measured using $\mathrm{H}_{2} \mathrm{O}_{2}$ as substrate ${ }^{17}$. A molar absorption of $43.6 \mathrm{M} / \mathrm{cm}$ was used to determine CAT activity. Enzymatic activity was expressed as $\mathrm{U} / \mathrm{mg}$ protein at $25^{\circ} \mathrm{C}$, one unit (U) of which was equal to 1 mole of $\mathrm{H}_{2} \mathrm{O}_{2}$ degraded $/ \mathrm{min} / \mathrm{mg}$ of protein.

\section{Glutathione peroxidase (GSH-Px, EC 1.11.1.9) activity}

GSH-Px activity was measured using t-butyl hydroperoxide as substrate ${ }^{18}$. The absorbance of reaction mixture was measured at $340 \mathrm{~nm}$ for $180 \mathrm{~s}$ in a spectrophotometer. A molar absorption of $6.22 \times 103 \mathrm{M} / \mathrm{cm}$ was used to determine enzyme activity, expressed as $\mathrm{U} / \mathrm{mg}$ protein at $37^{\circ} \mathrm{C}$. One unit (U) of activity was equal to $\mathrm{mM}$ of NADPH oxidized/min/ $\mathrm{mg}$ protein.

\section{Reduced glutathione (GSH) levels}

GSH was determined by its reaction with DTNB (Ellman's reagent) yielding a yellow chromophore, the absorbance of which was measured at $412 \mathrm{~nm}$ within $15 \mathrm{~min}$ spectrophotometrically ${ }^{19}$. GSH levels were determined from a standard curve and expressed as $\mu \mathrm{M} / \mathrm{mg}$ protein.

\section{Lipid peroxidation assay}

MDA (a thiobarbituric acid reactive species: TBARS) an indicator of lipid peroxidation was measured using 1,1,3,3 tetraethoxypropane as standard ${ }^{20}$. The absorbance of the reaction mixture was measured at $532 \mathrm{~nm}$ and the values were expressed as $\mathrm{nM}$ MDA /mg protein.

\section{Protein assay}

The Protein content of the samples was determined using Folin phenol reagent ${ }^{21}$.

\section{Statistical analysis}

Data were evaluated by one-way analysis of variance (ANOVA) with post-hoc analysis by Tukey Kramer multiple comparison test. Significance was set at $\mathrm{P}<0.05$. All data are presented as means \pm standard error (S.E.) of the means. Comparisons were done between the stress groups (RS; $1 \mathrm{~h}$ or $24 \mathrm{~h}$ after the stressor) and NS control group, and also between the $1 \mathrm{~h}$ and $24 \mathrm{~h}$ RS groups.

\section{RESULTS}

Effect of RS on the levels of monoamine and their metabolites in the selected brain regions:

\section{Frontal cortex}

As shown in Figure $1 \mathrm{~A}$ and $1 \mathrm{~B}$, there was a significant increase in the cortical DA $[\mathrm{P}<0.05-0.01]$, HVA $[\mathrm{P}<0.01-0.001]$ and 5-HT $[\mathrm{P}<0.01]$ levels in both the $1 \mathrm{~h}$ and $24 \mathrm{~h}$ RS groups as compared to the NS control group. However, the levels of NE $[\mathrm{P}<0.01]$ and 5-HIAA $[\mathrm{P}<0.05]$ were significantly altered only in the $1 \mathrm{~h}$ RS groups as compared to the NS control group. The post

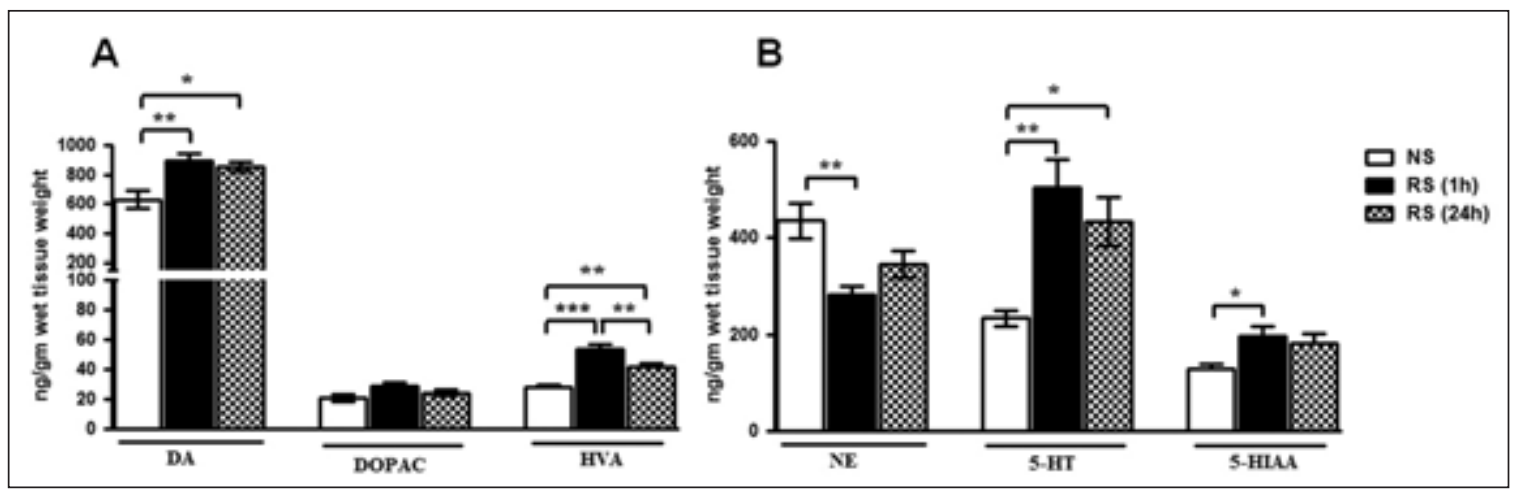

Figure 1: Histogram representing the levels of DA, DOPAC, HVA (A) NE, 5-HT and 5-HIAA (B) in the frontal cortex of control group (non-stress, NS) and groups exposed to restraint stress (RS; 1 h and $24 \mathrm{~h}$ after the stressor). Results are represented as mean \pm S.E.M.; $n=8$ rats per group. $* P<0.05, * * P<0.01$, *** $P<0.001$ vs. NS control group and between the 1 h and $24 h$ RS groups. (ANOVA, Tukey's Kramer multiple comparison test). 


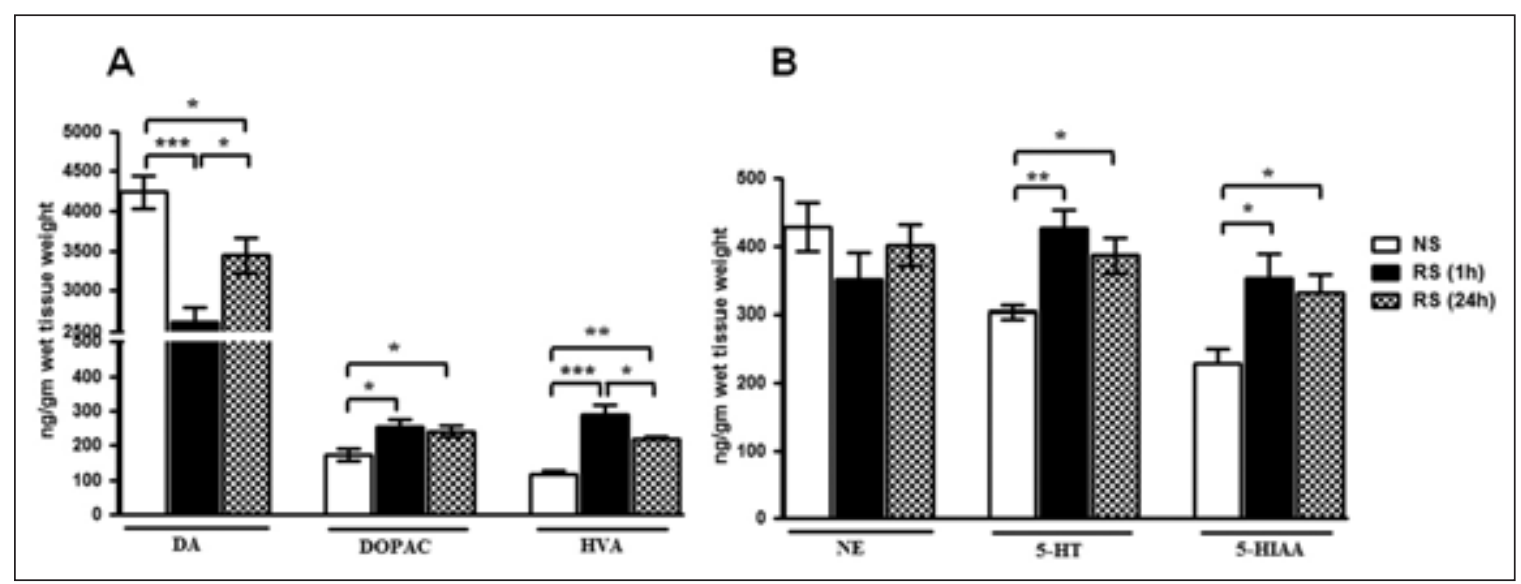

Figure 2: Histogram representing the levels of DA, DOPAC, HVA (A) NE, 5-HT and 5-HIAA (B) in the striatum of control group (non-stress, NS) and groups exposed to restraint stress (RS; $1 \mathrm{~h}$ and $24 \mathrm{~h}$ after the stressor). Results are represented as mean \pm S.E.M.; $n=8$ rats per group. $* P<0.05$, ** $P<0.01$, *** $P<0.001$ vs. NS control group and between the 1 h and $24 h$ RS groups. (ANOVA, Tukey's Kramer multiple comparison test).

hoc tests (Tukey Kramer) revealed no significant differences $[\mathrm{P}>0.05]$ in the levels of NE and 5-HIAA between the $1 \mathrm{~h}$ and $24 \mathrm{~h}$ RS groups. Further, the post hoc analysis showed a significant decrease in the levels of DA $[\mathrm{P}<0.05]$, HVA $[\mathrm{P}<0.01]$ and 5-HT $[\mathrm{P}<0.05]$ in the $24 \mathrm{~h}$ RS group when compared with $1 \mathrm{~h}$ RS group.

\section{Striatum}

Figure $2 \mathrm{~A}$ and $2 \mathrm{~B}$ depict that there was a significant decrease in the levels of striatal DA $[\mathrm{P}<0.05-0.001]$, with significantly increased DOPAC $[\mathrm{P}<0.05]$, HVA $[\mathrm{P}<0.05-0.001], 5-\mathrm{HT}$ $[\mathrm{P}<0.05-0.01]$ and 5-HIAA $[\mathrm{P}<0.05]$ levels in both the $1 \mathrm{~h}$ and $24 \mathrm{~h}$ RS groups when compared with the NS control group. Post hoc tests (Tukey Kramer) revealed a significant increase of the DA levels in the $24 \mathrm{~h}$ RS group when compared to the $1 \mathrm{~h}$ RS group. However, the levels of DOPAC, HVA, 5-HT and 5-HIAA were significantly $[\mathrm{P}<0.05]$ decreased in the $24 \mathrm{~h} \mathrm{RS}$ group when compared with the $1 \mathrm{~h}$ RS group. The levels of NE altered insignificantly $[\mathrm{P}>0.05]$ in all the groups.

\section{Hippocampus}

As shown in Figure $3 \mathrm{~A}$ and $3 \mathrm{~B}$, there was a significant decrease in the DA $[\mathrm{P}<0.01-0.001]$ and NE $[\mathrm{P}<0.01-0.001]$ levels in both the $1 \mathrm{~h}$ and $24 \mathrm{~h}$ RS groups compared with the NS control group. The 5-HT and 5-HIAA levels were significantly $[\mathrm{P}<0.05]$ increased in the $1 \mathrm{~h} \mathrm{RS}$ group only. Post hoc tests (Tukey Kramer) revealed significant differences in the NE $[\mathrm{P}<0.05]$ and 5-HT $[\mathrm{P}<0.05]$ levels when compared between the $1 \mathrm{~h}$ and $24 \mathrm{~h}$ RS groups.

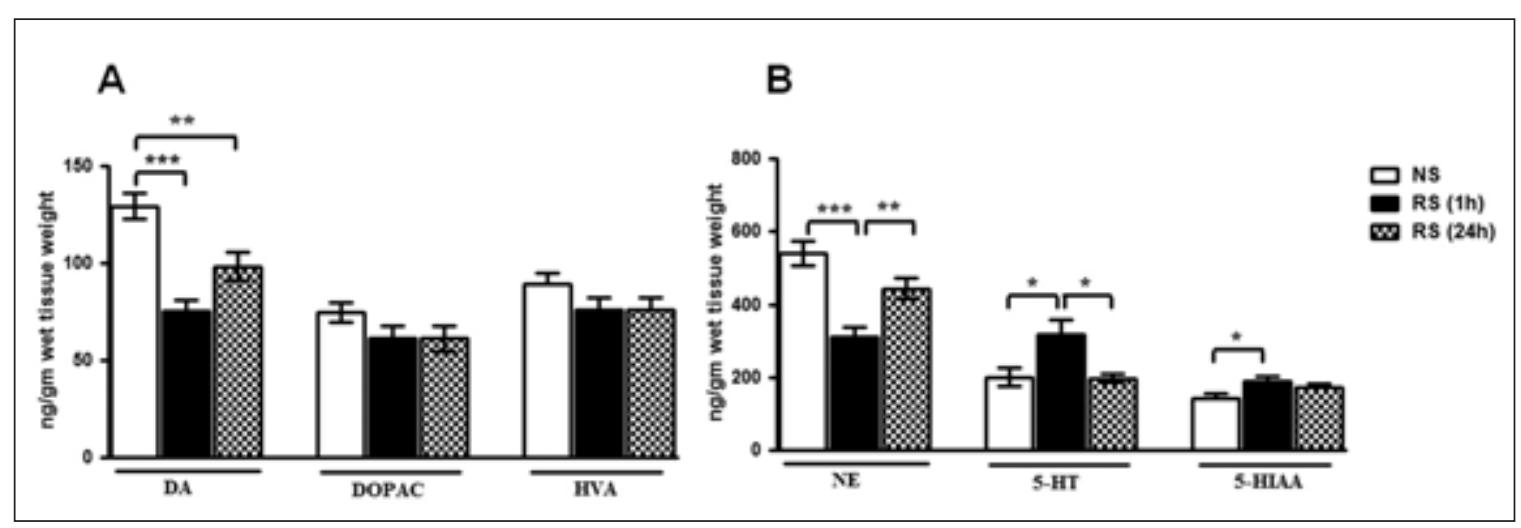

Figure 3: Histogram representing the levels of DA, DOPAC, HVA (A) NE, 5-HT and 5-HIAA (B) in the hippocampus of control group (non-stress, NS) and groups exposed to restraint stress $(R S ; 1 \mathrm{~h}$ and $24 \mathrm{~h}$ after the stressor). Results are represented as mean \pm S.E.M.; $n=8$ rats per group. $* P<0.05, * * P<0.01$, *** $P<0.001$ vs. NS control group and between the $1 \mathrm{~h}$ and $24 \mathrm{~h} R S$ groups. (ANOVA, Tukey's Kramer multiple comparison test). 
Table: Effect of restraint stress (RS) on in-vivo antioxidant status and lipid peroxidation

\begin{tabular}{|c|c|c|c|c|c|c|}
\hline Brain regions & Groups & $\begin{array}{c}\text { SOD } \\
\text { (U/mg } \\
\text { protein) }\end{array}$ & $\begin{array}{c}\text { CAT } \\
(\mathrm{U} / \mathrm{mg} \\
\text { protein }) \\
\end{array}$ & $\begin{array}{c}\text { GSH-Px } \\
\text { (U/mg } \\
\text { protein) }\end{array}$ & $\begin{array}{c}\text { GSH } \\
(\mu \mathrm{M} / \mathrm{mg} \\
\text { protein) }\end{array}$ & $\begin{array}{c}\text { MDA } \\
\text { (nM/mg } \\
\text { protein) } \\
\end{array}$ \\
\hline \multirow[t]{3}{*}{ Frontal Cortex } & NS & $5.11 \pm 0.46$ & $0.23 \pm 0.03$ & $0.026 \pm 0.003$ & $100.31 \pm 8.28$ & $7.26 \pm 0.67$ \\
\hline & RS (1h) & $8.56 \pm 0.62^{\mathrm{b}}$ & $0.25 \pm 0.04$ & $0.041 \pm 0.004^{\mathbf{b}}$ & $64.50 \pm 4.31^{\mathrm{b}}$ & $12.98 \pm 1.49^{\mathbf{b}}$ \\
\hline & $\mathrm{RS}(24 \mathrm{~h})$ & $7.49 \pm 0.71^{\mathrm{a}}$ & $0.31 \pm 0.03$ & $0.038 \pm 0.002^{\mathrm{a}}$ & $71.50 \pm 5.34^{\mathrm{a}}$ & $10.97 \pm 0.89$ \\
\hline \multirow[t]{3}{*}{ Striatum } & NS & $7.853 \pm 1.07$ & $0.17 \pm 0.02$ & $0.036 \pm 0.005$ & $160.3+9.35$ & $22.67 \pm 3.12$ \\
\hline & RS (1h) & $13.83 \pm 1.25^{\mathbf{b}}$ & $0.21 \pm 0.03$ & $0.062 \pm 0.004^{\mathbf{b}}$ & $102.5 \pm 5.06^{\mathrm{c}}$ & $42.33 \pm 3.53^{\mathrm{c}}$ \\
\hline & $\mathrm{RS}(24 \mathrm{~h})$ & $12.81 \pm 1.27^{\mathrm{a}}$ & $0.26 \pm 0.04$ & $0.055 \pm 0.003^{\mathrm{a}}$ & $129.2 \pm 9.71^{\mathrm{a}}$ & $37.51 \pm 1.99^{\mathbf{b}}$ \\
\hline \multirow[t]{3}{*}{ Hippocampus } & NS & $4.21 \pm 0.34$ & $0.15 \pm 0.02$ & $0.038 \pm 0.003$ & $85.5 \pm 4.01$ & $16.83 \pm 1.62$ \\
\hline & RS (1h) & $5.59 \pm 0.79$ & $0.22 \pm 0.03$ & $0.051 \pm 0.006$ & $70.67+4.3^{\mathrm{a}}$ & $20.67 \pm 0.84$ \\
\hline & RS (24h) & $5.09 \pm 0.35$ & $0.25 \pm 0.03$ & $0.049 \pm 0.004$ & $79.33+3.4$ & $19.33 \pm 1.52$ \\
\hline
\end{tabular}

Data expressed as mean \pm S.E.M.; $n=6$ rats per group, representing the changes in the antioxidant defense system and lipid peroxidation in the frontal cortex, striatum and hippocampus of control (non-stress, NS) and stressed (RS; $1 \mathrm{~h}$ and 24h after the stressor) groups. ${ }^{\mathrm{a}} \mathrm{P}<0.05,{ }^{\mathrm{b}} \mathrm{P}<0.01,{ }^{\mathrm{c}} \mathrm{P}<0.001$ are the significant ranges when comparison was done between the stressed ( $1 \mathrm{~h}$ or $24 \mathrm{~h} \mathrm{RS}$ groups) and NS control group; whereas ${ }^{\mathrm{x}} \mathrm{P}<0.05$, ${ }^{\mathrm{y}} \mathrm{P}<0.01,{ }^{\mathrm{P}} \mathrm{P}<0.001$ are considered when comparison was done between the $1 \mathrm{~h}$ and 24h RS groups. (ANOVA, Tukey's Kramer multiple comparison test).

Effect of RS on the antioxidant enzyme activities in selected brain regions:

Alterations in the activities of SOD, CAT and GSH-Px are depicted in the Table.

SOD: SOD activity was significantly increased in both the $1 \mathrm{~h}$ and 24h RS groups in the frontal cortex $[\mathrm{P}<0.05-0.01]$, striatum $[P<0.05-0.01]$, with no significant $[P>0.05]$ change in the hippocampus compared to the NS control group. Further, post hoc tests (Tukey Kramer) revealed no significant differences [P>0.05] in SOD activities between the $1 \mathrm{~h}$ and $24 \mathrm{~h}$ RS groups in any of the brain regions (Table).

CAT: There was no significant change in the CAT activity in any of the groups studied. Further, there were no significant differences [P>0.05] in CAT activities between the $1 \mathrm{~h}$ and $24 \mathrm{~h}$ $\mathrm{RS}$ groups in any of the brain regions (Table).

GSH-Px: There was a significant increase in the GSH-Px activity in the frontal cortex $[\mathrm{P}<0.05-0.01]$ and striatum $[\mathrm{P}<0.05$ $0.01]$ in both the $1 \mathrm{~h}$ and $24 \mathrm{~h}$ RS groups, with no significant differences in the hippocampus [P>0.05] compared to the NS control group. Further, post hoc tests (Tukey Kramer) revealed no significant differences [P>0.05] in GSH-Px activity between the $1 \mathrm{~h}$ and $24 \mathrm{~h}$ RS groups in any of the brain regions (Table).

\section{Effect of RS on the GSH levels in the selected brain regions:}

As shown in the Table, the non-enzymatic antioxidant defense marker GSH was significantly decreased in the frontal cortex $[\mathrm{P}<0.05-0.01]$ and striatum $[\mathrm{P}<0.05-0.001]$ both in the $1 \mathrm{~h}$ and $24 \mathrm{~h}$ RS groups, whereas in the hippocampus the significant $[\mathrm{P}<0.05]$ decrease was observed only in the $1 \mathrm{~h}$ RS group compared to the NS control group. Further, the post hoc tests (Tukey Kramer) revealed no significant differences [P>0.05] in the GSH levels between the $1 \mathrm{~h}$ and $24 \mathrm{~h}$ RS groups in any of the brain regions.

\section{Effect of RS on lipid peroxidation in the selected brain regions:}

The Table shows that there was a significant increase in the lipid peroxidation expressed as increased MDA levels in both the $1 \mathrm{~h}$ and $24 \mathrm{~h} \mathrm{RS}$ groups in the striatum [P<0.01-0.001], while in the frontal cortex $[\mathrm{P}<0.01]$ the increase was observed only in the $1 \mathrm{~h}$ RS group with no significant change in the hippocampus $[\mathrm{P}>0.05]$ compared to the NS control group. Further, the post hoc tests (Tukey Kramer) revealed no significant differences [P>0.05] in the MDA levels between the $1 \mathrm{~h}$ and $24 \mathrm{~h}$ RS groups in any of the brain regions.

\section{Discussion}

The stress-induced effects are an outcome of altered activity of different mechanisms such as central neurotransmitters, neurohormonal factors, particularly those linked with the HPAaxis, and free radical generation ${ }^{2,3}$. The development of stressinduced disorders might be associated with a temporal prolongation of initial stress response in discrete brain regions. These responses are believed to be developed during the first exposure of stress and/or novel environment. Thus, in the present investigation we aimed to evaluate the initial response of monoaminergic and oxidative systems in various important brain regions in RS condition after different time intervals. We have 
selected the RS model to investigate changes induced by a short acting severe stressors. It represents the reaction to an immediate threat. Among the various stress models, RS has been used extensively and accepted widely as it produces both physical and inescapable psychological stress ${ }^{22}$.

The present study demonstrates that the exposure of a single immobilization stress episode caused a differential initial response in the monoaminergic and anti-oxidant systems in a brain region specific manner, and most of these changes last for at least $24 \mathrm{~h}$ after the stress exposure, indicating their long lasting effects. RS led to a significant decrease of NE levels in the frontal cortex and hippocampus. The NE system is known to be activated by stress; although only for a short duration ${ }^{23}$, which could explain the decreased levels of NE by RS, as the stressor applied were of relatively longer duration $(2.5 \mathrm{hr})$. Also, increased corticosterone level during $\mathrm{RS}^{13}$ can reduce the efficacy of NE to enhance firing frequency with a delay of one to two hours, through a GC-dependent mechanism ${ }^{24}$.

Results also demonstrated a differential and brain region specific DA response. RS significantly increased DA levels in the frontal cortex while the levels decreased in the striatum and hippocampus both in the $1 \mathrm{~h}$ and $24 \mathrm{~h}$ RS groups. The increased DOPAC and HVA levels in the striatum and increased HVA level in the frontal cortex probably reflect increased synthesis and/or metabolism of DA. The increased DA metabolism may be due to either the increase in intraneuronal monoamine oxidase (MAO) activity to DOPAC and/or by catechol-O-methyl transferase to HVA. Our observations concur with reports suggesting that acute stressful conditions activate monoaminergic systems leading to an increase in the extracellular levels of NE, DA and 5-HT in different regions of brain ${ }^{5,6,23}$. Generally, it has been thought that exposure to acute stress led to a transient activation of monoamine systems to restore homeostasis. However, our finding of decreased DA level in the striatum and hippocampus in response to RS warrants special attention. In the striatum the decreased DA level was accompanied by subsequent increases in DOPAC and HVA levels, suggesting increased conversion of DA to its metabolite in response to RS. On the other hand in the hippocampus, the DA level was decreased with no significant changes in its metabolite levels. The hippocampus is rich in cholinergic innervations and a reciprocal relation exists between acetylcholine and DA responses in brain ${ }^{25}$. The decrease of DA in the hippocampus could be attributed to decreased cholinesterase activity and excess acetylcholine turnover during acute stress conditions ${ }^{26}$. These differential monoamine responses could also be due to variations in their level of distribution, synthesis and degradation.

Increased 5-HT and 5-HIAA levels during RS, in all three brain regions, both in the $1 \mathrm{~h}$ and $24 \mathrm{~h} \mathrm{RS}$ group, could be attributed to an overall activation of 5-HT systems and subsequent increase in the firing rate of 5-HT neurons. The turnover and/or synthesis of 5-HT in the brain is reported to increase in response to physical and psychological stressors ${ }^{27,28}$.

The increased 5-HT and 5-HIAA levels could also be explained on the basis that an acute stress exposure activates tryptophan hydroxylase activity in the cortex and midbrain ${ }^{29}$.

Stressful stimuli adversely affect different brain regions and cause changes in the normal homeostasis of the anti-oxidant defense system ${ }^{30,31}$. However, the anti-oxidant system may respond diversely depending upon the different stress protocols used in various studies. In order to neutralize reactive oxygen species (ROS), the body uses enzymatic (SOD, CAT and GSH$\mathrm{Px}$ ) and non-enzymatic (GSH) antioxidant systems. In our study, RS significantly enhanced the activity of defensive anti-oxidant enzymes SOD and GSH-Px in the frontal cortex and striatum, and these changes remain altered even after $24 \mathrm{~h}$ of the stress exposure. Interestingly, in the hippocampus there were no significant changes in the activity of these enzymes. The CAT activity was increased in all three brain regions but did not reach statistical significance. This differential elevation of oxidative markers in the selected brain regions may arise from the differences in the antioxidant buffering capacities or differential susceptibilities to oxidative stress. The increased activity of SOD is an indicator of a relative increase in super oxide radical production and suggests that the brain's antioxidant machinery is activated in response to excessive generation of free radicals. Enhanced SOD activity catalyzes the conversion of superoxide anions to $\mathrm{H}_{2} \mathrm{O}_{2}$ which in turn could stimulate the second line of defence which includes GSH-Px and CAT ${ }^{32}$. These enzymes convert $\mathrm{H}_{2} \mathrm{O}_{2}$ into water and molecular oxygen, rationalizing the cause for the elevation of these two during RS. However, a lesser change in CAT activity as compared to GSH-Px could be attributed to the fact that in brain CAT activity has been found to be low and confined to peroxisomes ${ }^{33}$. GSH-Px, therefore, appears to be primarily responsible for the destruction of excess $\mathrm{H}_{2} \mathrm{O}_{2}$ formed in nervous tissue ${ }^{1}$. The increased GSH-Px activity also indicates the increase in cellular peroxides. Furthermore, such an increase in the activities of enzymes during acute stress exposure can be related to long term compensatory mechanisms, including activity modulation of enzymes related to ROS catabolism. Decreased GSH levels could be explained on the basis that loss of GSH may occur during an oxidative stress event due to its increased rate of utilization ${ }^{3,31}$. The significant elevation of lipid peroxidation marker (MDA) in the frontal cortex and striatum is in agreement with previous reports ${ }^{30,31}$. However, the unaffected lipid peroxidation in the hippocampus might reflect the difference in the microenvironment (concentration of monoamines and anti-oxidants) of various brain regions.

We found simultaneous alterations in both monoamines and oxidative processes, pointing towards the possibility of interconnection between the two systems during RS. These observations are strengthened by other reports too, showing some direct and indirect involvement of the production of free radicals in brain with catecholamine metabolism ${ }^{34}$. Elevated catecholamine levels may undergo auto-oxidation, in which electrons are generated that in turn can produce $\mathrm{ROS}^{35}$. DA forms ROS through its metabolism by MAO and by autooxidation. Molecular oxygen can react with DA forming quinones and semiquinones, which can further deplete GSH with simultaneous generation of $\operatorname{ROS}^{12}$. Thus, increased monoamine metabolite concentrations and turnover could be one of the contributing factors for increased oxidative load and altered antioxidant enzyme activities during RS. These results support the hypothesis of Siraki and O'Brien ${ }^{11}$ that biogenic amines form pro-oxidant radicals. The increase in DA turnover and metabolism might produce $\mathrm{H}_{2} \mathrm{O}_{2}$ through MAO activity ${ }^{12}$, which could be responsible for neuronal membrane lipid peroxidation observed in our study. 
Since increased activity of antioxidant enzymes is observed only in the frontal cortex and striatum and not in the hippocampus, it could be hypothesized that monoamineassociated oxidation might be the primary source of ROS during RS conditions. Considering the fact that both these brain regions have extensive amounts of DA, its oxidation could contribute more oxidative burden in these brain regions than in the hippocampus. These oxidative changes in the frontal cortex and striatum, although decreased with time, (evidenced in the $24 \mathrm{~h}$ RS group), still remained significantly altered compared to the control values. Thus we cannot rule out the possibility that RSinduced alteration of monoamine metabolism in these brain regions contributes to the increased oxidative load.

Altered 5-HT transmission might also contribute to oxidative load during RS in different brain regions as other reports ${ }^{10,11}$ also highlighted the potential neurotoxic role for 5-HT metabolites arising from superoxide mediated oxidation. Thus, the perturbed central monoamine response and metabolism could amplify the oxidative load during RS, in a region specific manner. Thus, the different levels of free radicals in various brain regions during acute stress exposure may determine modulation of neurotransmitters either through the changes in neurotransmitter levels and/or by effects on receptor functioning. Thus, both the monoaminergic and oxidative systems may influence each other's functioning.

\section{Conclusions}

The present study clearly suggested that the frontal cortex and striatum are more sensitive to oxidative burden than the hippocampus, which could be related to the parallel monoamine perturbations during RS. The pattern of RS-induced monoamine and oxidative changes after $1 \mathrm{~h}$ and $24 \mathrm{~h}$ later were similar when compared with control group. Although, in a few instances the changes in these parameters decreased significantly when compared between the $1 \mathrm{~h}$ and $24 \mathrm{~h}$ RS groups. Nevertheless, the changes induced by RS remained significantly altered even after $24 \mathrm{~h}$ of stress regime compared to control values, indicating that the observed changes may have long lasting effects. The present findings support the hypothesis that neurotransmitter intervention in oxidative damage should be seriously considered, however understanding its precise mechanisms warrants further studies. Our study contributes to the understanding of the neurochemical and antioxidant defense system interactions that are possibly involved in the biological basis of central stressinduced disorders such as depression, anxiety and other neurological conditions.

Our study provides a rational look into the possible interactions between the two systems and stipulates the compensatory mechanisms operating during acute stress responses which are particular to precise brain regions. Studies suggest implications for pharmacological interventions targeting both central monoamines and cellular antioxidants as a potential stress management strategy for protecting against stress-induced brain disorders.

\section{ACKNOWLEDGEMENT}

The authors thank the Indian Council of Medical Research (ICMR), New Delhi, India for providing financial support.

\section{REFRENCES}

1. Andersen JK. Oxidative stress in neurodegeneration: cause or consequence? Nat Med. 2004 Jul;10 Suppl:S18-25.

2. Jankord R, Herman JP. Limbic regulation of hypothalamopituitary-adrenocortical function during acute and chronic stress. Ann NY Acad Sci. 2008 Dec;1148:64-73.

3. Zafir A, Banu N. Modulation of in vivo oxidative status by exogenous corticosterone and restraint stress in rats. Stress. 2009;12(2):167-77.

4. Maier SF, Ryan SM, Barksdale CM, Kalin NH. Stressor controllability and the pituitary-adrenal system. Behav Neurosci. 1986 Oct;100(5):669-74.

5. Rasheed N, Ahmad A, Pandey CP, Chaturvedi RK, Lohani M, Palit G. Differential response of central dopaminergic system in acute and chronic unpredictable stress models in rats. Neurochem Res. $2010 \mathrm{Jan} ; 35(1): 22-32$.

6. Fujino K, Yoshitake T, Inoue $\mathrm{O}$, et al. Increased serotonin release in mice frontal cortex and hippocampus induced by acute physiological stressors. Neurosci Lett. 2002 Mar 1;320(1-2): 91-5.

7. Liu J, Wang X, Shigenaga MK, Yeo HC, Mori A, Ames BN. Immobilization stress causes oxidative damage to lipid, protein, and DNA in the brain of rats. Faseb J. 1996 Nov;10(13):1532-8.

8. Perez-Nievas BG, Garcia-Bueno B, Caso JR, Menchen L, Leza JC. Corticosterone as a marker of susceptibility to oxidative/ nitrosative cerebral damage after stress exposure in rats. Psychoneuroendocrinology. 2007 Jul;32(6):703-11.

9. Radak Z, Sasvari M, Nyakas C, et al. Single bout of exercise eliminates the immobilization-induced oxidative stress in rat brain. Neurochem Int. $2001 \mathrm{Jul} ; 39(1): 33-8$.

10. Wrona MZ, Dryhurst G. Oxidation of serotonin by superoxide radical: implications to neurodegenerative brain disorders. Chem Res Toxicol. 1998 Jun;11(6):639-50.

11. Siraki AG, O'Brien PJ. Prooxidant activity of free radicals derived from phenol-containing neurotransmitters. Toxicology. 2002 Aug 1;177(1):81-90.

12. Miyazaki I, Asanuma M. Dopaminergic neuron-specific oxidative stress caused by dopamine itself. Acta Med Okayama. 2008 Jun;62(3):141-50.

13. Rai D, Bhatia G, Sen T, Palit G. Comparative study of perturbations of peripheral markers in different stressors in rats. Can J Physiol Pharmacol. 2003 Dec;81(12):1139-46.

14. Glowinski J, Iversen LL. Regional studies of catecholamines in the rat brain. I. The disposition of $[3 \mathrm{H}]$ norepinephrine, $[3 \mathrm{H}]$ dopamine and $[3 \mathrm{H}]$ dopa in various regions of the brain. $\mathbf{J}$ Neurochem. 1966 Aug;13(8):655-69.

15. Kim C, Speisky MB, Kharouba SN. Rapid and sensitive method for measuring norepinephrine, dopamine, 5-hydroxytryptamine and their major metabolites in rat brain by high-performance liquid chromatography. Differential effect of probenecid, haloperidol and yohimbine on the concentrations of biogenic amines and metabolites in various regions of rat brain. J Chromatogr. 1987 Jan 16;386:25-35.

16. Misra HP, Fridovich I. The role of superoxide anion in the autoxidation of epinephrine and a simple assay for superoxide dismutase. J Biol Chem. 1972 May 25;247(10):3170-5.

17. Aebi H. Catalase in vitro. Methods Enzymol. 1984;105:121-6.

18. Flohe L, Gunzler WA. Assays of glutathione peroxidase. Methods Enzymol. 1984;105:114-21.

19. Sedlak J, Lindsay RH. Estimation of total, protein-bound, and nonprotein sulfhydryl groups in tissue with Ellman's reagent. Anal Biochem. 1968 Oct 24;25(1):192-205.

20. Ohkawa H, Ohishi N, Yagi K. Assay for lipid peroxides in animal tissues by thiobarbituric acid reaction. Anal Biochem. 1979 Jun;95(2):351-8.

21. Lowry OH, Rosebrough NJ, Farr AL, Randall RJ. Protein measurement with the Folin phenol reagent. J Biol Chem. 1951 Nov;193(1):265-75.

22. Pacak K, Palkovits M. Stressor specificity of central neuroendocrine responses: implications for stress-related disorders. Endocr Rev. 2001 Aug;22(4):502-48. 
23. Hellriegel ET, D'Mello AP. The effect of acute, chronic and chronic intermittent stress on the central noradrenergic system. Pharmacol Biochem Behav. 1997 May-Jun;57(1-2):207-14.

24. Joels M, Karst H, Krugers HJ, Lucassen PJ. Chronic stress: implications for neuronal morphology, function and neurogenesis. Front Neuroendocrinol. 2007 Aug-Sep;28(2-3): 72-96.

25. Vakalopoulos C. Neuropharmacology of cognition and memory: a unifying theory of neuromodulator imbalance in psychiatry and amnesia. Med Hypotheses. 2006;66(2):394-431.

26. Das A, Rai D, Dikshit M, Palit G, Nath C. Nature of stress: differential effects on brain acetylcholinesterase activity and memory in rats. Life Sci. 2005 Sep 16;77(18):2299-311.

27. Inoue T, Tsuchiya K, Koyama T. Regional changes in dopamine and serotonin activation with various intensity of physical and psychological stress in the rat brain. Pharmacol Biochem Behav. 1994 Dec;49(4):911-20.

28. Miura H, Qiao H, Ohta T. Attenuating effects of the isolated rearing condition on increased brain serotonin and dopamine turnover elicited by novelty stress. Brain Res. 2002 Feb 1;926(1-2):10-17.

29. Singh VB, Onaivi ES, Phan TH, Boadle-Biber MC. The increases in rat cortical and midbrain tryptophan hydroxylase activity in response to acute or repeated sound stress are blocked by bilateral lesions to the central nucleus of the amygdala. Brain Res. 1990 Oct 15;530(1):49-53.
30. Zafir A, Banu N. Antioxidant potential of fluoxetine in comparison to Curcuma longa in restraint-stressed rats. Eur J Pharmacol. 2007 Oct 15;572(1):23-31.

31. Sahin E, Gumuslu S. Alterations in brain antioxidant status, protein oxidation and lipid peroxidation in response to different stress models. Behav Brain Res. 2004 Dec 6;155(2):241-8.

32. Fridovich I. Superoxide radical and superoxide dismutases. Annu Rev Biochem. 1995;64:97-112.

33. Gaunt GL, de Duve C. Subcellular distribution of D-amino acid oxidase and catalase in rat brain. J Neurochem. 1976 Apr;26(4): $749-59$.

34. Venarucci D, Venarucci V, Vallese A, et al. Free radicals: important cause of pathologies refer to ageing. Panminerva Med. 1999 Dec;41(4):335-9.

35. Carpagnano GE, Kharitonov SA, Resta O, Foschino-Barbaro MP, Gramiccioni E, Barnes PJ. 8-Isoprostane, a marker of oxidative stress, is increased in exhaled breath condensate of patients with obstructive sleep apnea after night and is reduced by continuous positive airway pressure therapy. Chest. 2003 Oct;124(4): 1386-92. 